\title{
Mifepristone versus placebo to treat uterine myoma: a double-blind, randomized clinical trial
}

This article was published in the following Dove Press journal:

International Journal of Women's Health

24 June 2013

Number of times this article has been viewed

\author{
Josep Lluis Carbonell Esteve' \\ Rita Acosta ${ }^{2}$ \\ Yasmirian Pérez ${ }^{2}$ \\ Barbara Rodriguez ${ }^{2}$ \\ Isabel Seigler ${ }^{2}$ \\ Carlos Sanchez ${ }^{2}$ \\ Giuseppe Tomasi ${ }^{3}$ \\ 'Mediterránea Médica Clinic, \\ Valencia, Spain; ${ }^{2}$ Eusebio Hernández \\ Gynecology and Obstetrics Teaching \\ Hospital, Havana, Cuba; ${ }^{3}$ University \\ of The Basque Country, Bilbao, Spain
}

Correspondence: Josep Lluis Carbonell

Esteve

Mediterránea Médica Clinic,

C/Salvador Guinot, I4, Valencia 460I7,

Spain

Tel +3496358 6020

Fax +3496378 5485

Email schja@infomed.sld.cu;

josepcarbon@yahoo.es

\begin{abstract}
Objective: To evaluate the efficacy, safety, and quality of life of $5 \mathrm{mg}$ mifepristone per day compared with a placebo in treating uterine fibroids.

Design: Randomized, double-blind clinical study.

Location: Eusebio Hernández Gynecology and Obstetrics Teaching Hospital, Havana, Cuba.

Subjects: One hundred twenty-four subjects with symptomatic uterine fibroids.

Treatment: One daily capsule of $5 \mathrm{mg}$ mifepristone or a mifepristone placebo over 3 months.
\end{abstract}

Variables in evaluating safety: Changes in fibroid and uterine volumes, changes in symptom prevalence and intensity, and changes in quality of life.

Results: Three months into treatment, fibroid volume was reduced by $28.5 \%$ in the mifepristone group with an increase of $1.8 \%$ in the placebo group $(P=0.031)$. There were significant differences between the groups with respect to pelvic pain prevalence $(P=0.006)$, pelvic pressure $(P=0.027)$, rectal pain $(P=0.013)$, hypermenorrhea $(P<0.001)$, and metrorrhagia $(P=0.002)$ at the end of treatment. Amenorrhea was $93.1 \%$ and $4.3 \%$ in the mifepristone and placebo groups, respectively $(P<0.001)$. Treatment side effects were significantly greater in the mifepristone group. Estradiol levels did not differ significantly between the placebo and mifepristone groups at the end of treatment. Improvement in quality of life was significantly greater in the categories of "symptoms" $(P=0.004)$ and "activity" $(P=0.045)$ in the mifepristone group.

Conclusion: The $5 \mathrm{mg}$ dosage of mifepristone presented significantly superior efficacy compared to the placebo.

Keywords: mifepristone, leiomyoma, fibroid, antiprogestins

\section{Introduction}

Mifepristone administered in low doses over treatment periods of 3, 6, 9, and 12 months has proved its therapeutic efficacy for treating uterine fibroids with regard to: (1) symptomatic improvement, (2) reduction of fibroid and/or uterine volume, and (3) quality of life. ${ }^{1-11}$ It has also shown itself to be useful prior to surgery on uterine fibroids. ${ }^{10,12}$

Recently, the European Union has approved the commercialization of a selective progesterone receptor modulator for presurgical treatment of uterine fibroids: ulipristal acetate (Esmya ${ }^{\circledR}$ Gedeon Richter Ltd, Budapest, Hungary), which has an antiprogestin effect somewhat inferior to mifepristone. ${ }^{13}$

Amongst the main side effects of mifepristone are (1) endometrial thickening, (2) hot flushes, (3) raised aspartate aminotransferase (ASAT) and alanine aminotransferase (ALAT). These have all been widely studied except for hot flushes, which are examined closely in this study along with variations in estradiol in blood serum, which could be associated with hot flushes. 
There are two published studies comparing 5 and $10 \mathrm{mg}$ doses of mifepristone against a placebo over 3 and 6 months, respectively, but with relatively small sample sizes. ${ }^{14,15} \mathrm{~A}$ Health Care Research and Quality report criticized the notable absence of clinical studies demonstrating the efficacy of the different treatments available for uterine fibroids. ${ }^{16}$ The findings of this study will help towards filling this gap.

The aim of this study is to evaluate the efficacy, safety, and changes in quality of life brought about by $5 \mathrm{mg}$ daily mifepristone versus a placebo over 3 months in the treatment of symptomatic uterine myomas.

\section{Materials and methods Design}

This controlled, double-blind, randomized clinical trial of $5 \mathrm{mg}$ mifepristone versus a placebo to treat uterine myomas was approved by the "Eusebio Hernández" Gynecology and Obstetrics Teaching Hospital Scientific Committee, Havana, Cuba. Subjects were recruited from the hospital classification department consultancy and primary health care units. All subjects gave their informed consent to participate in the study. The clinical study was carried out in accordance with the Declaration Of Helsinki and the Good Clinical Practice (GCP) guidelines and began in March 2012 with the last subject to be included being evaluated in September 2012, after 3 months of treatment with mifepristone.

\section{Subjects}

Female volunteers, 18 years old or older, with uterine fibroids were eligible for the study. Inclusion and exclusion criteria were the same as those used in a previous study of ours. ${ }^{10}$

\section{Treatment}

Group 1: one placebo tablet taken orally every day for 3 months. Group 2: one tablet of mifepristone taken orally every day for 3 months. The placebo and mifepristone tablets were supplied by Litaphar Laboratory, Guipúzcoa, Spain. The tablets were identical in shape, size, appearance, and color and the packaging carried a code ("mifepristone A" or "mifepristone B") and a number only known to the Litaphar Laboratory; this code was revealed once the initial data processing was completed.

\section{Examinations performed}

Complete gynecological examination and abdominal or vaginal ultrasound examination of the uterus was done at the beginning and end of treatment. Fibroid volume was calculated using the formula:

$$
\text { Fibroid volume }=0.524 \mathrm{ABC},
$$

where $\mathrm{A}, \mathrm{B}$, and $\mathrm{C}$ are the diameters of the sphere in each of the three planes and are expressed in cubic centimeters. ${ }^{12}$ If the subject had more than one myoma, the measurement of the biggest was taken and its variations were used to evaluate efficacy. The volume of the uterus was measured using the Equation 1. Ultrasonography was used to calculate endometrial thickness in millimeters. All ultrasound calculations were carried out with SSD-4000 ultrasound diagnostic equipment (Aloka Co, Ltd, Tokyo, Japan); two doctors specializing in ultrasound carried out the measurements. Calibrations taken at the end of each treatment visit were performed by sonographers who were ignorant of previous measurements, knowing only the localization of the myoma to be measured. Blood samples were taken for hematological tests and the determination of hepatic transaminases at the first and last visit. Prior to treatment, samples of cervical tissue were taken from all subjects for cervical cytology, and an endometrial biopsy was performed if any of the following criteria applied: (1) endometrial thickness $>8 \mathrm{~mm}$; (2) episodes of vaginal bleeding lasting more than 10 days; (3) vaginal bleeding during the 3 weeks prior to onset of menstruation; or (4) copious vaginal bleeding. The process was repeated again after 45 days of treatment if any of the same criteria applied, and at the end of treatment, all subjects had this testing done, regardless of the criteria mentioned earlier. The Horne and Blithe ${ }^{17}$ and Mutter et al ${ }^{18}$ criteria were used to interpret the biopsies.

\section{Control visits and evaluation}

There were evaluation visits at the beginning and end of treatment. There were no follow-up visits.

\section{Variables to evaluate efficacy}

The main variables to evaluate efficacy were the percentage changes in fibroid and uterus volumes previous to and after treatment. Other variables used to estimate efficacy were changes in the prevalence of pelvic pain, lumbar pain, rectal pain, pelvic pressure, urinary symptoms, dyspareunia, hypermenorrhea, and metrorrhagia. Pelvic pain intensity and hypermenorrhea were evaluated by a visual analog scale from 0 to 10 , where 0 represented absence of symptoms and 10 their maximum (severe pain, bleeding very abundant) value, as self-reported by each patient.

\section{Variables to evaluate safety}

The following variables were used to evaluate safety:

1. Changes in endometrial thickness, with evaluation undertaken at the beginning and end of treatment. 
2. Mifepristone side-effects: amenorrhea, hot flushes, nausea, dizziness, vomiting, fatigue/tiredness. The intensity of the hot flushes was evaluated by means of a visual analog scale, as described earlier.

3. Variations in ASAT and ALAT values before and after treatment.

4. Endometrial changes associated with selective progesterone receptor modulators. If the subject only had spotting lasting up to a maximum of 6 days, she was considered amenorrheic, however if she was bleeding for any duration or spotting for 7 or more days, we considered she was not amenorrheic.

\section{Variables to determine hormonal and biochemical changes produced by mifepristone}

Blood samples were taken to determine estradiol $(\mathrm{pg} / \mathrm{mL})$, progesterone $(\mathrm{nmol} / \mathrm{L})$, testosterone $(\mathrm{ng} / \mathrm{mL})$, luteinizing hormone, (IU/L), follicle-stimulating hormone (IU/L), and prolactin (mIU/L) levels between days 18 and 21 of the menstrual cycle before treatment started and 5 to 7 days before treatment was finished. All hormones were determined by radioimmunoassay in the Isotope Centre (CENTIS), Havana, Cuba, except estradiol, which was determined by enzyme-linked immunosorbent assay in the Finlay Institute, Havana, Cuba.

\section{Quality of life}

This was evaluated before treatment started and after the end of treatment by means of the Uterine Fibroid Symptom and Quality of Life (UFS-QOL) test ${ }^{19}$ using a scale of 1 to 100 points to indicate changes observed in quality of life. The sections in this test evaluate different aspects of quality of life: sexual activity, self-control, energy and mood, etc. An increase in score means an improvement in quality of life, whereas such an improvement is indicated by a reduction in score in the "symptoms" section. ${ }^{19}$

\section{Number of subjects to be included}

The expected reduction in fibroid volume was the variable used to estimate the number of subjects to be included in the study. As a reference point, we used results obtained in previous studies ${ }^{11-15}$ with $5 \mathrm{mg}$ mifepristone; it was assumed that, with $5 \mathrm{mg}$ mifepristone, the fibroid volume would reduce by between at least $35 \%$ and $40 \%$ by the end of treatment with respect to its initial volume, whilst, with the placebo, the reduction would not exceed $10 \%$. A power analysis carried out with $\mathrm{G}^{*}$ Power software (version 3.0.10; University of Kiel, Kiel, Germany) determined that, with 44 subjects in each treatment group, it was possible to detect the difference between the two groups with a type I error of $5 \%$ and a type II error of $10 \%$. In total, the study sample size was increased by approximately $30 \%$, to 62 subjects in each group, 124 in the whole study, in order to offset dropouts during treatment, especially in the placebo group, or subjects being excluded for not complying with protocol.

\section{Assignment to treatment groups}

Staff not directly involved in the study prepared sealed opaque envelopes, each envelope containing a card indicating "mifepristone A" or "mifepristone B," where "A" is placebo and " $\mathrm{B}$ " is mifepristone $5 \mathrm{mg}$. Once the subject had been evaluated in line with the inclusion and exclusion criteria and had signed the informed consent, the envelope corresponding to the subject's numbered incorporation into the study was opened and she was included in the treatment group indicated on the card contained in the envelope. As the study design was double-blind, neither the doctor nor the patient knew if the subject had been assigned to the $5 \mathrm{mg}$ mifepristone group or the placebo group.

\section{Presentation of results and statistics}

The results are presented in absolute frequencies, percentages, averages, standard deviations, and 95\% confidence intervals for the average values in fibroid and uterine volumes. Pearson's Chi-square test, Student's $t$-test, and normal approximation for proportions were used to evaluate homogeneity between the two treatment groups. For comparisons within each treatment group of the continuous variables of efficacy, safety, and hormonal determinations, Student's $t$-test for independent samples and normal approximation for proportions were used to draw comparisons between the groups with respect to fibroid symptom prevalence and incidence of mifepristone side effects. In all cases, $P<0.05$ was considered significant and all tests were two-tailed. Data was processed using the SPSS 11.5 (IBM Corporation, Armonk, NY, USA).

\section{Results}

\section{Inclusion and adherence to treatment}

A total of 136 subjects were referred to the consultative research center, 14 of whom did not meet the inclusion criteria; thus $124 / 136(91.2 \%)$ subjects were included in the clinical trial, 62 in each treatment group, all of whom took the medication. The 3-month treatment was completed by $47 / 62$ (75.8\%) and 58/62 (93.5\%) subjects in the placebo and $5 \mathrm{mg}$ groups, respectively $(P=0.003)$. The 15 dropouts from the 
placebo group were as follows: one aborted and one ectopic pregnancy (both excluded due to breaching the protocol that set out the use of barrier contraceptives); one due to fear of biopsies; one due to venous thrombosis; one due to fear of taking the tablets; one due to suffering burns; and nine subjects who did not attend the end-of-treatment session. The reasons for the four dropouts from the $5 \mathrm{mg}$ mifepristone group were: one because she thought the treatment was not improving her condition and therefore discontinued it; one expelled a submucous fibroid 6 days after beginning treatment, although the fibroid chosen for sonography was intramural; one due to adverse reactions (nausea, vomiting, fatigue, and pain in the epigastrium over 11 days, which she attributed to mifepristone, having taken 48 tablets); and one due to high arterial blood pressure and fear of continuing to take the tablets (Figure 1).

\section{Initial variables and comparison between treatment groups}

In Table 1, the general characteristics of all subjects included in the clinical trial are presented. There were no significant differences between the treatment groups for any of the general characteristics with the exception of hemoglobin $(P=0.018)$. In all, 20/124 (16.1\%) subjects were sent from the hospital infertility consultancy due to their infertility being associated with the leiomyoma; there were no significant differences between the treatment groups $(P=0.164)$. One single myoma was present in 26/62 (41.9\%) and 22/62 (35.5\%) subjects in the placebo and $5 \mathrm{mg}$ mifepristone groups, respectively $(P=0.500)$. In total, 49/124 (39.5\%), 1/124 (0.8\%), and 74/124 (59.7\%) subserous, submucous, and intramural myomas were studied, respectively, and there were no significant differences between the treatment groups with respect to the distribution of the fibroids studied $(P=0.288)$.

\section{Efficacy}

Efficacy evaluation was based on the 47 and 58 subjects in the placebo and mifepristone groups, respectively, who completed treatment. Tables 2 and 3 show the changes in fibroid and uterine volume in each group, respectively. There was no reduction in fibroid volume in $31 / 47(66.0 \%)$ and $11 / 58$ $(19.0 \%)$ subjects in the placebo and mifepristone groups, respectively $(P<0.001)$. There was no reduction in uterine size in $34 / 47(72.3 \%)$ and $13 / 58(22.4 \%)$ subjects in the placebo and mifepristone groups, respectively $(P<0.001)$. Table 4 shows the changes in symptom prevalence associated with the fibroid in each study group at the beginning and end of treatment. There was a significant increase in average hemoglobin scores in the mifepristone group from pretreatment values to values on termination of treatment: $10.9 \pm 2.0 \mathrm{~g} / \mathrm{L}$ to $11.7 \pm 2.1 \mathrm{~g} / \mathrm{L}(P=0.023)$. In the placebo group, the initial and final hemoglobin scores were identical;

Primary health units and classification consulting department from hospital identified women with symptomatic leiomyomas, $\mathrm{n}=136$

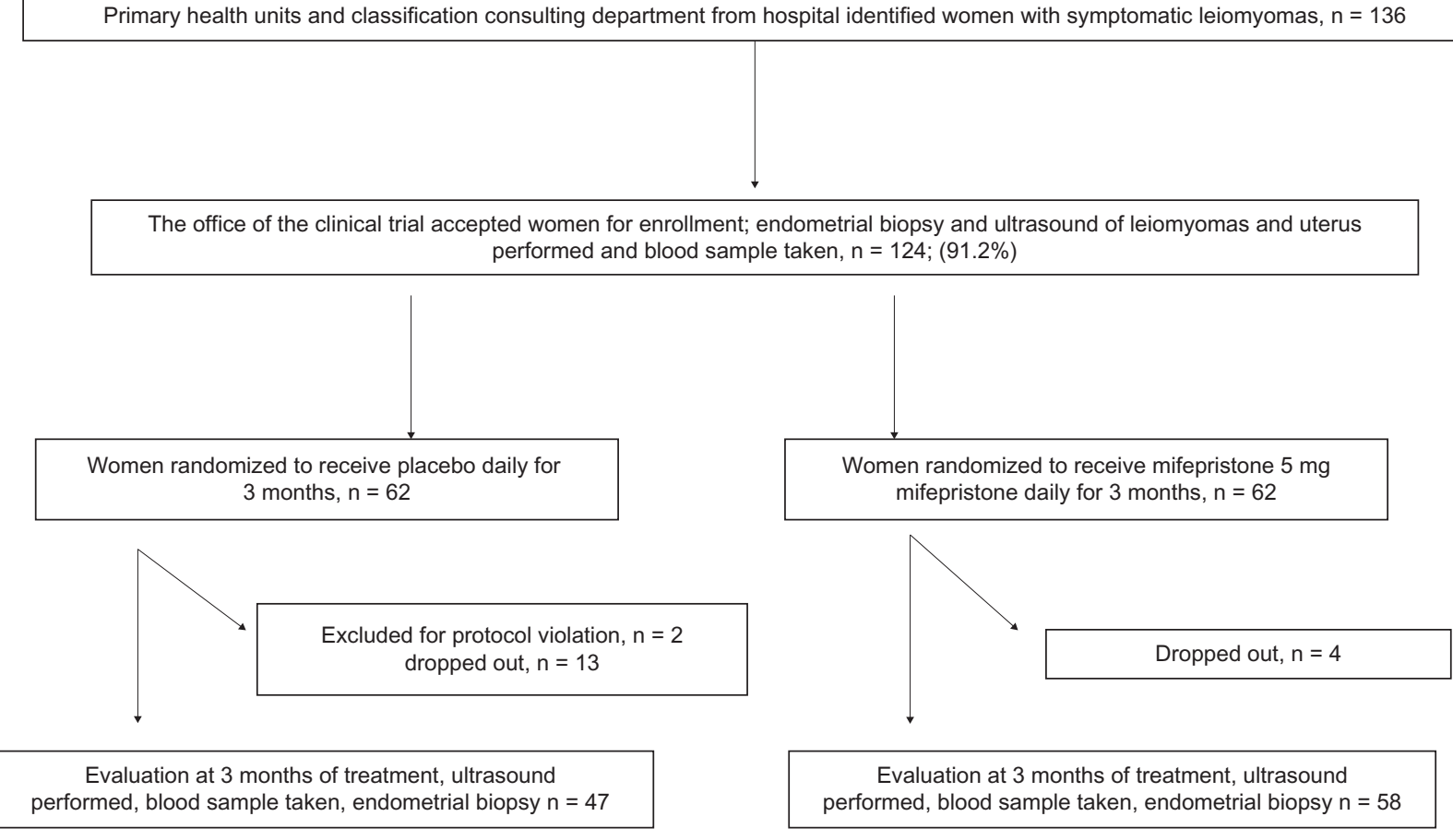

Figure I Flow chart for the trial. 
Table I Characteristics of the subjects by treatment groups

\begin{tabular}{lcc}
\hline Characteristic & $\mathbf{n}=\mathbf{6 2}$ & \\
\cline { 2 - 3 } & Placebo & \multicolumn{1}{c}{ Mifepristone } \\
& & $\mathbf{5 ~} \mathbf{~ m g}$ \\
\hline Age (years) & $37.8 \pm 6.6$ & $39.1 \pm 6.6$ \\
Body mass index $\left(\mathrm{kg} / \mathrm{m}^{2}\right)$ & $25.8 \pm 4.3$ & $26.1 \pm 4.6$ \\
Gravidity & $2.6 \pm 2.1$ & $3.1 \pm 2.8$ \\
Parity & $0.5 \pm 0.7$ & $0.6 \pm 0.8$ \\
Abortion & $1.6 \pm 1.5$ & $1.6 \pm 1.7$ \\
Fibroids volume (cc) & $119 \pm 95$ & $124 \pm 94$ \\
Uterine volume (cc) & $416 \pm 200$ & $447 \pm 239$ \\
Endometrial thickness (mm) & $7.6 \pm 2.3$ & $7.3 \pm 1.9$ \\
Hemoglobin (g/dL) & $11.8 \pm 1.6$ & $11.0 \pm 2.0$ \\
Menses duration (days) & $5.9 \pm 1.6$ & $5.7 \pm 1.8$ \\
Aspartate aminotransferase (IU) & $20.6 \pm 8.1$ & $22.3 \pm 9.9$ \\
Alanine aminotransferase (IU) & $17.5 \pm 8.7$ & $19.7 \pm 7.9$ \\
Race & & \\
$\quad$ White & $20(32.3)$ & $22(35.5)$ \\
Black & $26(41.9)$ & $27(43.5)$ \\
Afro-Cuban & $16(25.8)$ & $13(21.0)$ \\
\hline
\end{tabular}

Note: Values are presented as mean \pm standard deviation or $n(\%)$.

there were no significant differences between the treatment groups in final hemoglobin values.

\section{Safety}

Amenorrhea was present 3 months into treatment in 2/47 (4.3\%) and 54/58 (93.1\%) subjects in the placebo and mifepristone groups, respectively $(P<0.001)$. Hot flushes were reported at some point during treatment by $4 / 47$ (8.5\%) and $14 / 58(24.1 \%)$ subjects in the placebo and mifepristone groups, respectively $(P=0.017)$. In total, 5/18 (27.8\%) subjects reported hot flushes at night, $9 / 18$ (50.0\%) subjects during the day, and 4/18 (22.2\%) subjects at any time, the differences being asymptotically significant between the groups $(P=0.052)$, with the mifepristone group having $8 / 14$ $(57.1 \%)$ subjects who suffered hot flushes at night versus $1 / 4$ $(25.0 \%)$ subjects in the placebo group. In the placebo and mifepristone groups, the average number of hot flush episodes over 24 hours were $2.0 \pm 2.0$ times a day and $2.2 \pm 1.2$ times a day, respectively $(P=0.851)$; over a week was $3.2 \pm 2.1$ days with episodes and $4.1 \pm 2.0$ days with episodes $(P=0.451)$, respectively. The hot flush episode duration was significantly greater in the mifepristone group than in the placebo group, at $3.6 \pm 3.2$ minutes versus $1.2 \pm 0.5$ minutes $(P=0.019)$, respectively. The intensity of the hot flushes in the mifepristone group was similar to that in the placebo group, $4.5 \pm 1.3$ and $5.8 \pm 2.5(P=0.210)$, respectively. Nausea was significantly more frequent in the mifepristone group than in the placebo group, with $13 / 58$ (2.4\%) and $3 / 47$ (6.4\%) cases $(P=0.011)$, respectively. The feeling of fatigue was also significantly more frequent in the mifepristone group than in the placebo group, with $10 / 58(17.2 \%)$ and $3 / 47(6.4 \%)$ cases $(P=0.047)$, respectively. Only $2 / 58(4.3 \%)$ subjects in the mifepristone group reported headaches. Table 5 shows changes in endometrial thickness between the beginning and end of treatment. There were two subjects with high aspartate transaminase in the placebo group with scores of 59.3 and 99.9 IU and three subjects in the mifepristone group (48.0, 48.8 , and 78.6 IU), with reference values of $46 \mathrm{IU}$ at the end of the treatment. With regards to alanine transaminase, there were three subjects in the placebo group with high scores of 54.1, 68.0, and 68.1 IU, and three subjects in the mifepristone group with high scores of 68.0, 69.0, and 96.0 IU, with reference values of $49 \mathrm{IU}$ at the end of the treatment. Between the beginning and end of treatment, 45/47 (95.7\%) and $12 / 58(20.7 \%)$ subjects in the placebo and mifepristone groups, respectively, reported some irregular bleeding $(P<0.001)$; the average number of days for such bleeding was: $25.1 \pm 4.9$ days and $9.0 \pm 7.9$ days in the placebo and mifepristone groups, respectively $(P<0.001)$. Subjects in the placebo group had normal menstrual cycles, with the exception of two subjects who only menstruated once in the 3-month treatment period and reported amenorrhea.

\section{Endometrial biopsy}

A pretreatment endometrial biopsy was performed on $10 / 124(8.1 \%)$ subjects, with the diagnosis being secretory endometrium. At the end of treatment all subjects were indicated for endometrial biopsy. Seven subjects refused to undergo the procedure (one in the placebo group and

Table 2 Changes in fibroid volumes (cc) by treatment groups and evaluation periods ${ }^{a}$

\begin{tabular}{llllcr}
\hline Evaluation time & Group & n & Mean \pm SD & 95\% Cl for difference & Change (\%) $^{\text {P-value }}$ \\
\hline Before treatment & Placebo & 47 & $119 \pm 96$ & -31.2 to 43.2 & 0.749 \\
& Mifepristone $5 \mathrm{mg}$ & 58 & $125 \pm 95$ & & \\
After 3 months of treatment & Placebo & 47 & $123 \pm 84$ & 3.4 to 66.6 & $0.03 \mathrm{I}$ \\
& Mifepristone $5 \mathrm{mg}$ & 58 & $88 \pm 79$ & & $28.5 \downarrow$ \\
\hline
\end{tabular}

Notes: aOnly for subjects who completed the treatment; ${ }^{b} t$-test (ANOVA).

Abbreviations: $\mathrm{Cl}$, confidence interval; SD, standard deviation. 
Table 3 Changes in uterine volumes (cc) by treatment groups and evaluation periods ${ }^{\mathrm{a}}$

\begin{tabular}{lllllll}
\hline Evaluation time & Group & $\mathbf{n}$ & Mean \pm SD & $\mathbf{9 5 \% ~ C l ~ f o r ~ d i f f e r e n c e ~}$ & Change (\%) $^{P \text {-value }}$ \\
\hline Before treatment & Placebo & 47 & $428 \pm 211$ & -57.7 to II7.7 & - & 0.499 \\
& Mifepristone $5 \mathrm{mg}$ & 58 & $458 \pm 236$ & & $2.6 \uparrow$ & 0.034 \\
After 3 months of treatment & Placebo & 47 & $439 \pm 210$ & 5.0 to 165 & $22.7 \downarrow$ & \\
& Mifepristone $5 \mathrm{mg}$ & 58 & $354 \pm 202$ & & \\
\hline
\end{tabular}

Notes: ${ }^{a}$ Only for subjects who completed the treatment; ${ }^{\mathrm{t}}$-test (ANOVA).

Abbreviations: $\mathrm{Cl}$, confidence interval; $\mathrm{SD}$, standard deviation.

six in the mifepristone group); seven samples were unsuitable for diagnosis: four in the placebo group and three in the mifepristone group. Of those samples deemed suitable, progesterone modulators associated endometrial changes (PAECs) were diagnosed in 12/49 (24.5\%) and 1/42 (2.4\%) subjects in the mifepristone and placebo groups, respectively $(P=0.001)$. There were $7 / 42(16.7 \%)$ subjects diagnosed with proliferative endometrium in the placebo group and $8 / 49(16.3 \%)$ subjects in the mifepristone group; $34 / 42$ $(80.9 \%)$ subjects had secretory endometrium in the placebo group and 29/49 (59.2\%) subjects in the mifepristone group.

\section{Hormones}

Tables 6 and 7 compare hormonal determinations between the treatment groups before and at the end of treatment.

Table 4 Prevalence of symptoms before and at end of treatment by groups ${ }^{a}$

\begin{tabular}{|c|c|c|c|}
\hline Fibroid symptoms & Placebo & $5 \mathrm{mg}$ & $P$-value ${ }^{b}$ \\
\hline \multicolumn{4}{|l|}{ Pelvic pain } \\
\hline Before & $30(63.8)$ & $47(81.0)$ & 0.024 \\
\hline End & $24(5 I .1)$ & $16(27.6)$ & 0.006 \\
\hline \multicolumn{4}{|l|}{ Pelvic pressure } \\
\hline Before & $33(70.2)$ & $4 \mid(70.7)$ & 0.479 \\
\hline End & $25(53.2)$ & $20(34.5)$ & 0.027 \\
\hline \multicolumn{4}{|l|}{ Urinary symptoms } \\
\hline Before & $16(34.0)$ & $22(37.9)$ & 0.340 \\
\hline End & $13(27.7)$ & $19(32.8)$ & 0.286 \\
\hline \multicolumn{4}{|l|}{ Lumbar pain } \\
\hline Before & $24(5 I .1)$ & $34(58.6)$ & 0.289 \\
\hline End & $14(29.8)$ & $21(36.2)$ & 0.244 \\
\hline \multicolumn{4}{|l|}{ Rectal pain } \\
\hline Before & $10(21.3)$ & $13(22.4)$ & 0.444 \\
\hline End & $9(19.1)$ & $3(5.2)$ & 0.013 \\
\hline \multicolumn{4}{|l|}{ Dyspareunia } \\
\hline Before & $13(27.7)$ & $18(31.0)$ & 0.353 \\
\hline End & $9(19.1)$ & $8(13.8)$ & 0.324 \\
\hline \multicolumn{4}{|l|}{ Hypermenorrhea } \\
\hline Before & $30(63.8)$ & $45(77.6)$ & 0.060 \\
\hline End & $30(63.8)$ & $2(3.4)$ & $<0.001$ \\
\hline \multicolumn{4}{|l|}{ Metrorrhagia } \\
\hline Before & $9(19.1)$ & $14(24.1)$ & 0.269 \\
\hline End & $6(12.8)$ & $0(0.0)$ & 0.002 \\
\hline
\end{tabular}

Notes: Data are presented as $n(\%) .{ }^{a}$ Only for subjects who completed the study

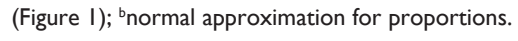

Figure 2 shows changes in estradiol values in both groups before and at the end of treatment.

\section{Quality of life}

The UFS-QOL questionnaires provided before and after treatment to evaluate changes in quality of life were completed by $40 / 47(85.1 \%)$ subjects in the placebo group and $48 / 58$ $(82.6 \%)$ subjects in the mifepristone group who finished the treatment. Tables $8-10$ present these results.

\section{Discussion}

\section{Efficacy}

The reduction in fibroid volume observed in this study is the lowest of all the studies carried out by our research program after treatment lasting 3 months. ${ }^{5,7,8,10}$ The reduction percentages in uterine volume are similar to those obtained in previous studies. ${ }^{5,7,8,10}$ Likewise, the present study's results are similar to the other two published placebo group studies, demonstrating a notable superiority on the part of mifepristone. ${ }^{4,12}$ The superiority of mifepristone over the placebo is also shown in the disappearance of the significant differences that were present between the average hemoglobin scores in the two groups before treatment, with the average hemoglobin score in the mifepristone group rising at the end of treatment. This is consistent if we take into account that the amenorrhea percentage in the mifepristone group was significantly higher than in the placebo group.

\section{Symptoms}

The superiority of mifepristone over the placebo is also sufficiently demonstrated with the almost complete disappearance of symptoms in the mifepristone group with $P$-values being significant in all symptoms except urinary alterations, lower back pain, and dyspareunia.

\section{Side effects}

This is the first study to closely monitor hot flushes, which were well-tolerated by our subjects as they were infrequent and of low intensity, and which led to no dropouts. Obviously, 
Table 5 Changes in endometrial thickness $(\mathrm{mm})$ by treatment groups and evaluation periods ${ }^{\mathrm{a}}$

\begin{tabular}{lllcccc}
\hline Evaluation time & Group & n & Mean \pm SD & 95\% Cl for difference & Changes (\%) & $\boldsymbol{P}_{\text {-value }}$ \\
\hline Before treatment & Placebo & 47 & $7.4 \pm 2.0$ & -0.76 to 0.76 & - & 1.000 \\
& Mifepristone 5 mg & 58 & $7.4 \pm 1.9$ & & \\
After 3 months of treatment & Placebo & 47 & $8.4 \pm 2.8$ & 0.8 to 3.0 & $13.5 \% \uparrow$ & 0.001 \\
& Mifepristone 5 mg & 58 & $10.3 \pm 2.7$ & & $39.2 \% \uparrow$ & \\
\hline
\end{tabular}

Notes: a Only for subjects who completed the treatment; ${ }^{b} t$-test (ANOVA).

Abbreviations: $\mathrm{Cl}$, confidence interval; SD, standard deviation.

the difference between both groups with regard to hot flushes is significant, it being of note that subjects in the placebo group reported hot flushes without taking any chemical medicine. Yes, there were significant differences between both groups with respect to nausea and fatigue, but the prevalence of these symptoms was very low. The difference between both groups vis-à-vis raised transaminases was not significant and in both cases was of minimum clinical significance given their resultant scores, which leads us to wonder whether mifepristone really does induce significant raised transaminases and whether these subclinical hikes are occasionally due to other causes. The average increase in post-treatment endometrial thickness was significantly higher in the mifepristone group given the climate of mifepristone-induced estrogen predominance. The results of the post-treatment endometrial biopsies revealed no cases of simple hyperplasia in either of the two groups and the only noticeable difference between them was the presence of PAECs in the previously stated mifepristone group percentages.

\section{Bleeding}

Bleeding patterns in both groups were difficult to compare since the mifepristone group was essentially amenorrheic

Table 6 Values of the hormonal determinations before treatment

\begin{tabular}{llllll}
\hline & Group & $\mathbf{n}$ & $\begin{array}{l}\text { Average } \\
(\mathbf{p g} / \mathbf{m L})\end{array}$ & $\begin{array}{l}\text { SD } \\
(\mathbf{p g} / \mathbf{m L})\end{array}$ & P-value \\
\hline Estradiol & Placebo & 16 & 1212 & 0.417 & 0.864 \\
& Mifepristone 5 mg & 15 & 1240 & 0.479 & \\
Progesterone & Placebo & 19 & 43.2579 & 42.0632 & 0.387 \\
& Mifepristone 5 mg & 25 & 34.1960 & 26.5156 & \\
Testosterone & Placebo & 34 & 2.6794 & 1.2689 & 0.710 \\
& Mifepristone 5 mg & 35 & 2.5657 & 1.2570 & \\
FSH & Placebo & 33 & 7.1909 & 11.0727 & 0.552 \\
& Mifepristone 5 mg & 35 & $8.797 \mid$ & 11.0659 & \\
LH & Placebo & 33 & 9.3697 & 12.8804 & 0.273 \\
& Mifepristone 5 mg & 35 & 6.5086 & 7.5602 & \\
Prolactin & Placebo & 33 & 643.6333 & 1070.4266 & 0.318 \\
& Mifepristone 5 mg & 35 & 447.9460 & 307.8712 & \\
\hline
\end{tabular}

Abbreviations: $\mathrm{FSH}$, follicle-stimulating hormone; $\mathrm{LH}$, luteinizing hormone; SD, standard deviation. and the placebo group menstruated regularly. The placebo group continued to have percentages of hypermenorrhea and metrorrhagia similar to those at the beginning of treatment while the mifepristone group only presented a little spotting and occasional days of irregular bleeding.

\section{Hormones}

As previously demonstrated, the use of mifepristone in low doses did not induce any significant hormonal change, as is shown here by the absence of differences in the comparative results of both treatment groups. It should be pointed out that in the mifepristone group, the estrogens did not decrease but rather, in this particular case, significantly increased their average post-treatment value, thus neutralizing the risk of osteoporosis and the serious consequences implicit in treating uterine fibroids by methods other than mifepristone, since although there were variations in average estrogen values, they were always within their accepted physiological range. Testosterone decreased significantly in the mifepristone group, but stayed within its accepted physiological range. Progesterone levels were not particularly valuable given the small subject sample size.

Table 7 Values of the hormonal determinations at the end of treatment

\begin{tabular}{llllll}
\hline & Group & $\mathbf{n}^{\mathbf{a}}$ & $\begin{array}{l}\text { Average } \\
(\mathbf{p g} / \mathbf{m L})\end{array}$ & $\begin{array}{l}\text { SD } \\
(\mathbf{p g} / \mathbf{m L})\end{array}$ & P-value \\
\hline Estradiol & Placebo & 16 & 1311 & 0.415 & 0.095 \\
& Mifepristone 5 mg & 16 & 1598 & 0.523 & \\
Progesterone & Placebo & $\mathrm{I}$ & 2.400 & - & 0.642 \\
& Mifepristone 5 mg & 5 & 5.5200 & 5.6650 & \\
Testosterone & Placebo & 19 & 3.7000 & 5.3617 & 0.189 \\
& Mifepristone 5 mg & 29 & 2.0138 & 0.7303 & \\
FSH & Placebo & 32 & 5.8438 & 3.5332 & 0.568 \\
& Mifepristone 5 mg & 35 & 6.6714 & 7.4152 & \\
LH & Placebo & 32 & 7.0688 & 6.5680 & 0.295 \\
& Mifepristone 5 mg & 35 & 5.5371 & 5.2759 & \\
Prolactin & Placebo & 33 & 764.9636 & 1317.2980 & 0.159 \\
& Mifepristone 5 mg & 35 & 433.8857 & 387.6284 & \\
\hline
\end{tabular}

Note: anly for subjects who had determinations both before and at the end of treatment.

Abbreviations: FSH, follicle-stimulating hormone; LH, luteinizing hormone; SD, standard deviation. 


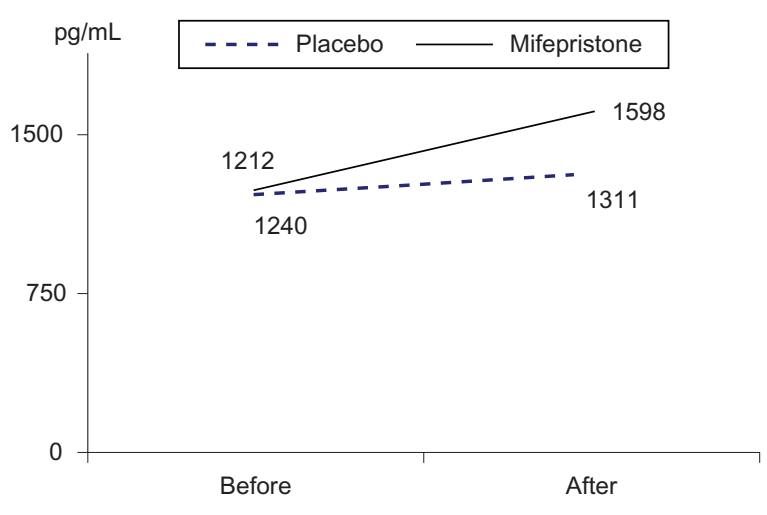

Figure 2 Changes in the determinations of estradiol before and after treatment.

\section{Quality of life}

Paradoxically, the placebo group displayed an improvement in quality of life according to the UFS-QOL similar to that of the mifepristone group, with the exception of the "symptoms" and "activity" sections. However, there was a marked tendency, statistically insignificant, towards a greater improvement in the mifepristone group, except in the "self-consciousness" section. We believe that behind this strange similarity there may be a bias in the composition of the test vis-à-vis the very low cultural level of

Table 8 UFS-QOL test ${ }^{19}$ scores before versus at the end of treatment in the placebo group

\begin{tabular}{|c|c|c|c|c|}
\hline & $\mathbf{n}$ & $\begin{array}{l}\text { Average } \\
(\mathrm{pg} / \mathrm{mL})\end{array}$ & $\begin{array}{l}\text { SD } \\
(\mathrm{pg} / \mathrm{mL})\end{array}$ & $P$-value \\
\hline \multicolumn{5}{|l|}{ Symptoms } \\
\hline Before & 40 & 43.2 & 23.0 & 0.752 \\
\hline After & 40 & 41.6 & 21.2 & \\
\hline \multicolumn{5}{|l|}{ Concern } \\
\hline Before & 40 & 61.0 & 34.3 & 0.498 \\
\hline After & 40 & 65.9 & 29.6 & \\
\hline \multicolumn{5}{|l|}{ Activity } \\
\hline Before & 40 & 72.4 & 23.8 & 10.000 \\
\hline After & 40 & 72.4 & 24.3 & \\
\hline \multicolumn{5}{|l|}{ Energy } \\
\hline Before & 40 & 70.2 & 20.7 & 0.987 \\
\hline After & 40 & 70.3 & 25.2 & \\
\hline \multicolumn{5}{|l|}{ Control } \\
\hline Before & 40 & 69.6 & 26.1 & 0.913 \\
\hline After & 40 & 70.2 & 24.9 & \\
\hline \multicolumn{5}{|l|}{ Inhibition } \\
\hline Before & 40 & 70.8 & 22.0 & 0.554 \\
\hline After & 40 & 73.5 & 18.8 & \\
\hline \multicolumn{5}{|l|}{ Sexual } \\
\hline Before & 40 & 68.7 & 29.8 & 0.965 \\
\hline After & 40 & 68.4 & 34.3 & \\
\hline \multicolumn{5}{|l|}{ Total } \\
\hline Before & 40 & 69.0 & 20.5 & 0.798 \\
\hline After & 40 & 70.2 & 22.0 & \\
\hline
\end{tabular}

Abbreviations: SD, standard deviation; UFS-QOL, Uterine Fibroid Symptom and Quality of Life.
Table 9 UFS-QOL test ${ }^{19}$ scores before versus after treatment in the $5 \mathrm{mg}$ mifepristone group

\begin{tabular}{|c|c|c|c|c|}
\hline & $\mathbf{n}$ & $\begin{array}{l}\text { Average } \\
(\mathrm{pg} / \mathrm{mL})\end{array}$ & $\begin{array}{l}\text { SD } \\
(\mathrm{pg} / \mathrm{mL})\end{array}$ & $P$-value \\
\hline \multicolumn{5}{|l|}{ Symptoms } \\
\hline Before & 48 & 49.0 & 16.4 & \multirow[t]{2}{*}{$<0.001$} \\
\hline After & 48 & 29.3 & 17.7 & \\
\hline \multicolumn{5}{|l|}{ Concern } \\
\hline Before & 48 & 51.6 & 30.0 & \multirow[t]{2}{*}{0.001} \\
\hline After & 48 & 74.2 & 31.9 & \\
\hline \multicolumn{5}{|l|}{ Activity } \\
\hline Before & 48 & 66.6 & 22.5 & \multirow[t]{2}{*}{0.001} \\
\hline After & 48 & 82.4 & 21.9 & \\
\hline \multicolumn{5}{|l|}{ Energy } \\
\hline Before & 48 & 63.9 & 22.5 & \multirow[t]{2}{*}{0.020} \\
\hline After & 48 & 75.8 & 26.9 & \\
\hline \multicolumn{5}{|l|}{ Control } \\
\hline Before & 48 & 64.3 & 22.0 & \multirow[t]{2}{*}{0.050} \\
\hline After & 48 & 74.1 & 26.3 & \\
\hline \multicolumn{5}{|l|}{ Inhibition } \\
\hline Before & 48 & 63.9 & 31.0 & \multirow[t]{2}{*}{0.282} \\
\hline After & 48 & 70.3 & 26.8 & \\
\hline \multicolumn{5}{|l|}{ Sexual } \\
\hline Before & 48 & 65.3 & 28.8 & \multirow[t]{2}{*}{0.144} \\
\hline After & 48 & 74.7 & 34.2 & \\
\hline \multicolumn{5}{|l|}{ Total } \\
\hline Before & 48 & 62.6 & 20.75 & \multirow[t]{2}{*}{0.003} \\
\hline After & 48 & 76.2 & 23.4 & \\
\hline
\end{tabular}

Abbreviations: SD, standard deviation; UFS-QOL, Uterine Fibroid Symptom and Quality of Life.

the sample and its high proportion of subjects of black ethnicity. In the Fiscella et al study, the improvement in quality of life was significantly greater in the mifepristone group. ${ }^{4}$

Table 10 Comparison of UFS-QOL test ${ }^{19}$ scores at the end of treatment between the placebo group and the mifepristone $5 \mathrm{mg}$ group

\begin{tabular}{|c|c|c|c|c|c|}
\hline & Group & $\mathbf{n}$ & $\begin{array}{l}\text { Average } \\
\text { (pg/mL) }\end{array}$ & $\begin{array}{l}\text { SD } \\
(\mathrm{pg} / \mathrm{mL})\end{array}$ & $P$-value \\
\hline \multirow[t]{2}{*}{ Symptoms } & Placebo & 40 & 41.6 & 21.2 & 0.004 \\
\hline & Mifepristone $5 \mathrm{mg}$ & 48 & 29.3 & 17.7 & \\
\hline \multirow[t]{2}{*}{ Concern } & Placebo & 40 & 65.9 & 29.6 & 0.213 \\
\hline & Mifepristone $5 \mathrm{mg}$ & 48 & 74.2 & 31.9 & \\
\hline \multirow[t]{2}{*}{ Activity } & Placebo & 40 & 72.4 & 24.3 & 0.045 \\
\hline & Mifepristone $5 \mathrm{mg}$ & 48 & 82.4 & 21.9 & \\
\hline \multirow[t]{2}{*}{ Energy } & Placebo & 40 & 70.3 & 25.2 & 0.325 \\
\hline & Mifepristone $5 \mathrm{mg}$ & 48 & 75.8 & 26.9 & \\
\hline \multirow[t]{2}{*}{ Control } & Placebo & 40 & 70.2 & 24.9 & 0.490 \\
\hline & Mifepristone $5 \mathrm{mg}$ & 48 & 74.1 & 26.3 & \\
\hline \multirow[t]{2}{*}{ Inhibition } & Placebo & 40 & 73.5 & 18.8 & 0.509 \\
\hline & Mifepristone $5 \mathrm{mg}$ & 48 & 70.3 & 26.8 & \\
\hline \multirow[t]{2}{*}{ Sexual } & Placebo & 40 & 68.4 & 34.3 & 0.392 \\
\hline & Mifepristone $5 \mathrm{mg}$ & 48 & 74.7 & 34.2 & \\
\hline \multirow[t]{2}{*}{ Total } & Placebo & 40 & 70.2 & 22.0 & 0.226 \\
\hline & Mifepristone $5 \mathrm{mg}$ & 48 & 76.2 & 23.4 & \\
\hline
\end{tabular}

Abbreviations: SD, standard deviation; UFS-QOL, Uterine Fibroid Symptom and Quality of Life. 


\section{Dropout figures}

The higher dropout rate in the placebo group may be an indication that mifepristone was more effective than the placebo.

\section{Internal validity}

Random assignment assured us of homogenous treatment groups, avoided selection bias, and guaranteed study blinding. The study size was big enough to demonstrate significant differences in fibroid volume reduction percentages between the placebo group and the subjects treated with mifepristone.

\section{External validity}

The clinical study included $91.2 \%$ of the subjects sent to the study consultancy, despite the inclusion and exclusion criteria possibly being very strict. This enabled us to treat nine out of every ten subjects with symptomatic uterine fibroids, thus indicating the feasibility of treating a large percentage of these subjects with mifepristone.

\section{Conclusion}

Mifepristone was significantly more effective in treating uterine fibroids compared to the placebo.

\section{Disclosure}

The authors report no conflicts of interest in this work.

\section{References}

1. Eisinger SH, Meldrum S, Fiscella K, le Roux HD, Guzick DS. Low-dose mifepristone for uterine leiomyomata. Obstet Gynecol. 2003;101(2):243-250

2. Eisinger SH, Bonfiglio T, Fiscella K, Meldrum S, Guzick DS. Twelve-month safety and efficacy of low-dose mifepristone for uterine myomas. J Min Invasiv Gynecol. 2005;12(3):227-233.

3. Eisinger SH, Fiscella J, Bonfiglio T, Meldrum S, Fiscella K. Open-label study of ultra low-dose mifepristone for the treatment of uterine leiomyomata. Eur J Obstet Gynecol. 2009;146(2):215-218.

4. Fiscella K, Eisinger SH, Meldrum S, Feng C, Fisher SG, Guzick DS. Effect of mifepristone for symptomatic leiomyomata on quality of life and uterine size. A randomized controlled trial. Obstet Gynecol. 2006;108(6): $1381-1387$
5. Carbonell Esteve JL, Acosta R, Heredia B, Pérez Y, Castañeda MC, Hernández AV. Mifepristone for the treatment of uterine leiomyomas. Obstet Gynecol. 2008;112(5):1029-1036.

6. Carbonell JL, Quiróz Rámirez GM, Borge A, Castellón Zapata LE, Cuadra Aragón W, Giuseppe Tomasi G. [Mifepristone $5 \mathrm{mg}$ versus $10 \mathrm{mg}$ daily to treat leiomyoma]. Prog Obstet Ginecol. 2009;10:1-8. Spanish.

7. Carbonell JL, Acosta R, PérezY, Yero MC, Seigler I, Heredia B. [Evolution of uterine leiomyoma after treatment with mifepristone. Randomized clinical trial]. Prog Obstet Ginecol. 2010;53(6):231-236. Spanish.

8. Carbonell JL, Acosta R, Heredia B, et al. [Mifepristone to treat uterine fibroids]. Rev Cub Gynecol Salud Reprod. 2010;36(2). Spanish.

9. Esteve JL, Acosta R, Pérez Y, Campos R, Hernández AV, Texidó CS Treatment of uterine myoma with 5 or $10 \mathrm{mg}$ mifepristone daily during 6 months, post-treatment evolution over 12 months: double-blind randomised clinical trial. Eur J Obstet Gynecol Reprod Biol. 2012; 161(2):202-208

10. Carbonell Esteve JL, Riverón AM, Cano M, et al. Mifepristone $2.5 \mathrm{mg}$ versus $5 \mathrm{mg}$ daily in the treatment of leiomyoma before surgery. Int $J$ Womens Health. 2012;4:75-84.

11. Carbonell JL, Acosta R, Pérez Y, et al. Safety and effectiveness of different dosage of mifepristone for the treatment of uterine fibroids: a double-blind randomized clinical trial. Int J Womens Health. 2013;5: $115-124$.

12. Engman M, Granberg S, Williams AR, Meng CX, Lalitkumar PG, Gemzell-Danielsson K. Mifepristone for treatment of uterine leiomyoma. A prospective randomized placebo controlled trial. Hum Reprod. 2009;24(8):1870-1879.

13. http://www.ema.europa.eu. EPAR summary for the public. Available from http://www.ema.europa.eu/docs/en_GB/document_library/ EPAR_-_Summary_for_the_public/human/002041/WC500124089. pdf. Accessed April 3, 2013.

14. Fiscella F, Bonfiglio T, Winters P, Eisinger SH, Fiscella K. Distinguishing features of endometrial pathology after exposure to the progesterone receptor modulator mifepristone. Hum Pathol. 2011;42(7):947-953.

15. Bagaria M, Suneja A, Vaid NB, Guleria K, Mishra K. Low-dose mifepristone in treatment of uterine leiomyoma: a randomized double-blind placebo-controlled trial. Aust N Z J Obstet Gynaecol. 2009;49(1): 77-83.

16. Management of Uterine Fibroids. AHRQ Publication NO 01-E051. Evidence report/technology assessment: Number 34. Rockville, MD: Agency for Healthcare Research and Quality; 2001. Available from: http://archive.ahrq.gov/clinic/epcsums/utersumm.htm. Accessed May 11, 2012.

17. Horne FM, Blithe DL. Progesterone receptor modulators and the endometrium: changes and consequences. Hum Reprod Update. 2007; 13(6):567-580.

18. Mutter GL, Bergeron C, Deligdisch L, et al. The spectrum of endometrial pathology induced by progesterone receptor modulators. Mod Pathol. 2008;21(5):591-598.

19. Spies JB, Coyne K, Guaou Guaou N, Boyle D, Skyrnarz-Murphy K, Gonzalves SM. The UFS-QOL, a new disease-specific and healthrelated quality of life questionnaire for leiomyoma. Obstet Gynecol. 2002;99(2):290-300.
International Journal of Women's Health

\section{Publish your work in this journal}

The International Journal of Women's Health is an international, peerreviewed open-access journal publishing original research, reports, editorials, reviews and commentaries on all aspects of women's healthcare including gynecology, obstetrics, and breast cancer. The manuscript management system is completely online and includes

\section{Dovepress}

a very quick and fair peer-review system, which is all easy to use. Visit http://www.dovepress.com/testimonials.php to read real quotes from published authors. 